\section{Genital Crohn's disease in a 6-year-old boy}

The male external genitalia may occasionally be affected in Crohn's disease; this almost invariably occurs as ulceration extending forwards from the perianal and perineal area on to the scrotum. ${ }^{1}$ We describe the case of a 6-year-old boy who presented with diffuse infiltration of the scrotum and foreskin due to Crohn's disease.

\section{Case report}

The patient had previously been admitted to another hospital at the age of 4 years for investigation of malaise, angular cheilitis, intermittent rectal bleeding, and painful defecation. Examination had shown several anal fistulae and an anal fissure. The fissure had been excised, and histological examination showed granulation tissue containing non-caseating epithelioid cell granulomas. Crohn's disease had been provisionally diagnosed. Spontaneous improvement occurred, and further investigation was deferred. After remaining well for 18 months, the boy developed recurrent swelling of the external genitalia. Episodes of increased swelling were accompanied by fever and tenderness with erythema of the scrotum and foreskin. The development of phimosis during one of these exacerbations necessitated circumcision. Histology of the excised foreskin showed numerous noncaseating epithelioid cell granulomas beneath a thinned epidermis, compatible with a diagnosis of Crohn's disease.

When admitted to this hospital at the age of $6 \frac{1}{2}$, the boy's height and weight were both on the 50th centile. An angular cheilitis was present, and there were granular, oedematous lesions on the labial gingival mucosa. The scrotum and foreskin were grossly swollen and indurated (see figure). The overlying skin was red and hot, and a few small vesicles and exudative lesions were present. Inguinal lymphadenopathy was absent, and physical examination was otherwise normal. Except for a raised erythrocyte sedimentation rate ( $34 \mathrm{~mm}$ in first hour) all haematological and biochemical investigation results were normal. There was no radiological evidence of large or small bowel disease. The Mantoux test $(1 / 1000)$ gave a negative result. Nose, throat, and scrotal skin swabs grew Lancefield group A $\beta$ haemolytic streptococci.

Rectal examination and sigmoidoscopy showed an anal fissure and a polypoid lesion in the anal canal; otherwise the appearances of the anal canal and rectum were normal. Biopsy of the anal fissure showed pronounced inflammation of the lamina propria with a dense infiltrate, mainly of plasma cells and lymphocytes. Histology of the anal polypoid lesion showed a similar diffuse subepithelial inflammatory infiltrate, together with prominent lymphoid aggregates containing germinal centres and non-caseating epithelial cell granulomas with giant cells. Biopsy specimens of the rectal mucosa showed patchy mucosal and submucosal inflammation with oedema and scattered non-caseating epithelioid cell granulomas. Biopsy of the gingival lesion showed a non-specific subepithelial chronic inflammatory infiltrate.

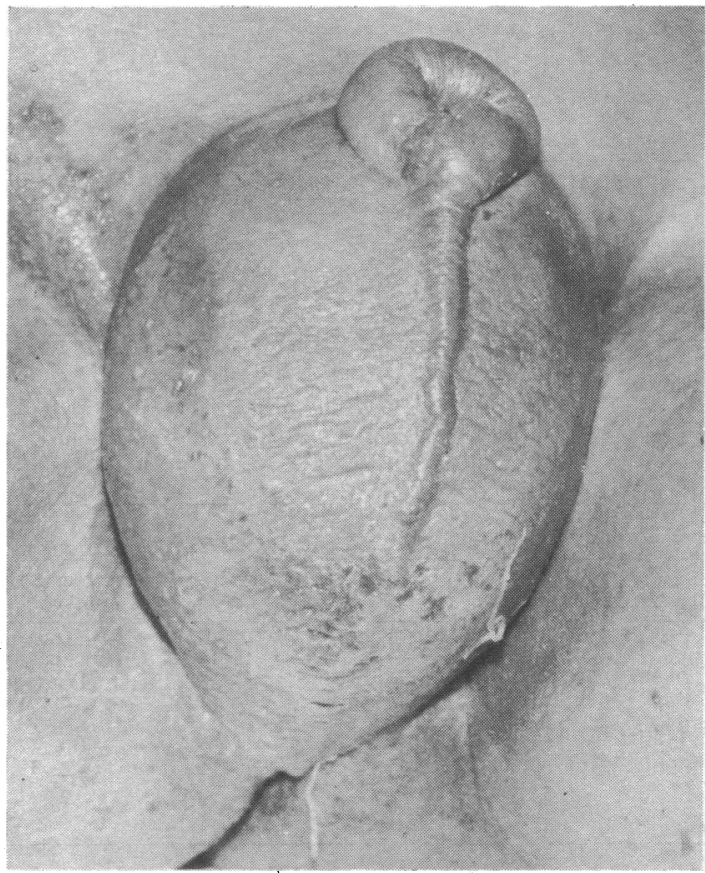

Appearance of external genitalia on admission.
Crohn's disease was diagnosed and treatment started with oral prednisolone $30 \mathrm{mg}$ daily. Before he started on steroid treatment there had been some reduction of the genital swelling with bed rest, scrotal support, and a course of oral phenoxymethylpenicillin to eradicate the $\beta$-haemolytic streptococci. Subsequently the genital swelling decreased rapidly until, three weeks after starting oral corticosteroids, the genitalia appeared normal. They have remained so, apart from minor fluctuations, while the dosage of prednisolone has been reduced over five months to $10 \mathrm{mg}$ on alternate days. Because of a tendency for early recolonisation of the skin by the same organism, phenoxymethylpenicillin is being given prophylactically ( $250 \mathrm{mg}$ twice a day).

\section{Comment}

The diagnosis of Crohn's disease in this patient rests on the histological finding of non-caseating epithelioid and giant-cell granulomas in the prepuce, in association with similar findings in the rectum and anal canal. It is supported by the concurrent presence of typical lesions of Crohn's disease in the perianal area and gingival mucosa. The involvement of the external genitalia appears to be of a type that has not previously been described.

We are grateful to Dr B C Morson and Professor J E Lennard-Jones for their invaluable advice.

Mountain, J C, Gut, 1970, 11, 18.

(Accepted 10 November 1977)

Hospital for Sick Children, Great Ormond Street, London WCIN
2JH
D J ATHERTON, MB, MRCP, research fellow
M MASSAM, MB, MRCP, senior house officer
R S WELLS, MD, FRCP, consultant dermatologist
J T HARRIES, MD, MRCP, reader in paediatrics
J R PINCOTT, MB, MRCPATH, senior lecturer in histopathology

\section{Hazard of chemical sy mpathectomy}

Since Diez ${ }^{1}$ first described lumbar sympathectomy in 1924 it has proved most effective for treating ischaemia of the leg, especially in patients not suited for arterial reconstruction. ${ }^{2}$ Such patients usually have widespread disease affecting coronary and cerebral vessels and may therefore be at considerable operative risk. For this reason chemical sympathectomy, by percutaneous injection of an aqueous solution of phenol, has become popular in several centres. We have now performed over 50 injections during the past three years using the technique described by Reid et al. ${ }^{3}$ We report our first serious complication.

\section{Case report}

A 70-year-old woman presented with increasing dyspnoea, ankle swelling, and pain in her right foot. She had been treated for some months with steroids for suspected fibrosing alveolitis, and had secondary polycythaemia. Right ventricular failure was present on admission. No pulses were palpable in the right leg and there were pregangrenous changes in the toes of her right foot. Control of her cardiac failure, and treatment with venesection, intravenous naftidrofuryl (Praxilene), and dextran 40 produced some improvement initially in her right foot. Later, however, deterioration with severe rest pain prompted us to carry out chemical sympathectomy. Two injections of $2.5 \mathrm{ml}$ of $6.7 \%$ aqueous phenol were made in the region of the right sympathetic chain at the levels of the third and fourth lumbar vertebrae. No blood or cerebrospinal fluid was obtained on aspirating at intervals before and during the injection. She made no complaints until two and a half hours after the procedure, when she commented that she had some weakness and anaesthesia of her legs. Examination confirmed that a satisfactory right lumbar sympathetic block had been achieved, but there was also anaesthesia and paresis on the right, corresponding to the nerve roots from L 3 downwards, and on the left from L5 downwards. Only very limited neurological improvement took place during the 32 days before she died from bronchopneumonia.

The necropsy report by. Drs A Gordon and A Busuttil stated that no macroscopic abnormality was observed in the cord or meninges. On microscopical examination there was demyelination and some axonal degeneration affecting predominantly the dorsal roots from $T 11$ to the conus. The demyelination tended to be most definite at the periphery of each root. There 
was no evidence of spinal arterial thrombosis. The cord showed some degeneration of the medial dorsal columns in keeping with the dorsal roo demyelination. There was no evidence of necrosis of the cord or of nerve roots. The findings were thought to be consistent with damage from intrathecal phenol.

\section{Discussion}

Haxton $^{4}$ reported one case of low spinal anaesthesia lasting for three hours after chemical sympathectomy and associated with unilateral quadriceps weakness persisting for three months. Our patient had an apparently permanent, severe neurological deficit in both legs. The unilateral vasodilatation suggests that the phenol was correctly placed. Extradural injection would be unlikely to produce such an extensive lesion. It was thought that there might have been damage to an unusually low artery of Adamkiewicz, producing low cord ischaemia but this was not sustained by the necropsy findings. Reid et al ${ }^{3}$ quoted three or four occasions on which cerebrospinal fluid was obtained during the procedure. Intrathecal injection of phenol is usually followed within minutes by paraesthesiae, anaesthesia, and paralysis, which usually last for only a few hours.

We assume that, despite the failure to obtain cerebrospinal fluid from the needle, and the absence of immediate neurological symptoms, some of the injected phenol must have entered the subarachnoid space.

We thank Professor J A Strong for allowing us to report on his patient.

${ }^{1}$ Diez, J, Boletines y Trabajos, Sociedad de Cirugía de Buenos Aires, 1924, 8 792.

2 Gillespie, J A, Lancet, 1960, 1, 891.

${ }^{3}$ Reid, W, Watt, J K, and Gray, T G, British fournal of Surgery, 1970, 57, 45.

${ }^{4}$ Haxton, H A, British Medical fournal, 1949, 1, 1026.

5 Kelly, R E, and Gautier-Smith, P C, Lancet, 1959, 2, 1102.

(Accepted 26 October 1977)

Departments of General Surgery and Medicine, Western General Hospital, Edinburgh EH4 2XU

R C SMITH, MB, FRCS, surgical registrar (now senior surgical registrar, Edinburgh Royal Infirmary)

N MCD DAVIDSON, BM, MRCP, senior lecturer in medicine and honorary consultant physician

C V RUCKLEY, CHM, FRCS, consultant surgeon

\section{Occupational exposure to petroleum products in men with acute non-lymphocytic leukaemia}

Chronic exposure to benzene ${ }^{12}$ and exposure to ionising radiation ${ }^{3}$ are environmental hazards increasing the risk of acute non-lymphocytic leukaemia (ANLL). Otherwise, however, occupational factors are not known to favour its development. We have noticed that in their work several of our men patients have handled petrol-driven motors or were otherwise exposed to motor fuels.

\section{Material, methods, and results}

The occupational titles and information on professional exposure to motor fuel were recorded in all men patients (50 cases) aged 20-65 (median 42.5) with ANLL seen at the Department of Internal Medicine at the University Hospital at Lund from 1969 up to and including May 1977. Three clinical groups served as controls: (1) 100 consecutive men patients aged 20-65 (median 43) treated for non-malignant disorders at our outpatien department in 1977 ; (2) 100 consecutive men aged 20-65 (median 39) treated at our outpatient department of allergic diseases; (3) 22 men aged 20-62 (median 41.5) with chronic myeloid leukaemia (CML) and 10 men aged 41-63 (median 52) with chronic lymphocytic leukaemia (CLL) seen during the same period as the patients with ANLL.

The occupational groups of men aged between 16 and 64 living in the county where our hospital is situated were obtained from the Swedish population census of 1970 and the number of groups indicating occupational exposure to petroleum products in this age group was obtained from the county council for the same year. Eighteen out of 50 (36\%) working men with ANLL were occupationally exposed to petroleum products or their combustion residues. Workers at filling stations, bus or truck drivers, operators of excavating machines or power saws, and road hauliers were typical occupations recorded for these patients. There was an especially large proportion of exposed patients in the age group 36-50 years-where nine out of 14 ANLL patients $(64 \%)$ had a history of occupational exposure to petroleum products (see table).

Occupational exposure to petroleum products in men with $A N L L$

\begin{tabular}{c|c|c|c}
\hline Age (years): & $20-35$ & $36-50$ & $51-65$ \\
\hline Exposed & 4 & 9 & 5 \\
Non-exposed & 13 & 5 & 14 \\
\hline Total & 17 & 14 & 19 \\
\hline
\end{tabular}

In each of the outpatient control groups 10 out of $100(10 \%)$ were exposed. The difference in exposure between the ANLL group and that in each of the control groups is significant ( $P=0.0002$, Fisher's exact probability test). In the patients with CML three out of $22(14 \%)$ were occupationally exposed and in the patients with CLL none of the nine patients. The difference between the patients with ANLL and the 31 patients with chronic leukaemias is significant $(P=0.006)$ and there is also a difference when the patients with ANLL are compared with patients with CML $(P=0.04)$ or patients with CLL $(P=0.03)$

In the county where our hospital is situated about 250000 men were 16-64 years old in 1970. Nearly 27000 -that is, 10-11\%-were occupationally exposed to petroleum products according to the occupational titles.

Chromosome analyses of bone marrow cells at diagnosis by the Giemsa banding technique were available in eight of the exposed patients and will be reported elsewhere.

\section{Discussion}

A large proportion (36\%) of our men patients aged between 20 and 65 with ANLL were occupationally exposed to petroleum products or their combustion residues. The corresponding figure found in our three control series treated at the same clinic was about $10 \%$ and data from the Swedish population census of 1970 indicate that the frequency of occupational exposure to petrol products is similar in the healthy, working male population. We therefore conclude that occupational exposure to motor fuel is unduly common among working men who develop ANLL, and our results indicate that some leukaemogenic factor(s) must be considered in the exposed patients.

Chronic exposure to benzene will increase the risk of ANLL, ${ }^{2}$ and petrol may contain $6-8 \%$ benzene. ${ }^{1}$ The haematological hazards of benzene in petrol have been pointed out by Verwilghen et $a l^{4}$ and Vigliani. ${ }^{1}$ Nevertheless, other leukaemogenic agents must be considered in individuals exposed to petrol or its combustion products. For example, road tanker drivers show an increased frequency of lymphocyte chromosome breakage irrespective of whether they transport petrol or milk. ${ }^{5}$

Unlike the patients with ANLL, occupational exposure to petrol products was not unduly common among the patients with CML or CLL. This result is in line with the findings in benzene-induced leukaemia, which is usually acute. ${ }^{12}$ Detailed environmental studies of patients with ANLL are needed to identify factors that may promote the development of the disease.

This work was supported by grants from the Swedish Cancer Society and the $\mathrm{J}$ and A Persson Foundation for Medical Research.

1 Vigliani, E C, Annals of the New York Academy of Sciences, 1976, 271, 143.

2 Infante, P F, et al, Lancet, 1977, 2, 76.

3 Heyssel, R, et al, Blood, 1960, 15, 313.

4 Verwilghen, R L, Van Dorpe, A, and Veulemans, H, Lancet, 1975, 2,1156

${ }^{5}$ Fredga, K, Reitalu, J, and Berlin, M, Expert Conference on Genetic Damage in Man Caused by Environmental Agents, Oslo, 11-13 May 1977 , in press.

(Accepted 15 November 1977)

\section{University Hospital, S-221 85 Lund, Sweden}

L BRANDT, MD, assistant professor, department of internal medicine

P G NILSSON, MD, consultant physician, department of internal medicine

F MITELMAN, MD, PHD, head of department, department of clinical genetics 